\title{
Riscos, vulnerabilidade e abordagem socioambiental urbana: uma reflexão a partir da RMC e de Curitiba ${ }^{1}$
}

\section{Risks, vulnerability and urban socio-environmental approach: a reflection on the CMA and Curitiba}

\author{
Francisco MENDONÇA*
}

Des forces naturelles devastent encore aujourd'hui de vastes territoires, mais l'urbanisation generalisée des populations mondiales, en accumulant hommes et activités sur des espaces retreints fait des villes des lieux eminemment vulnerables a tout agent perturbateur, qu'il soit exogéne ou endogéne, naturel ou technique.

Dubois-Maury; Chaline, 2002.

\section{RESUMO}

\begin{abstract}
A intensificação da urbanização na modernidade gerou inúmeros problemas relacionados à qualidade e às condições de vida na cidade do presente. Muitas têm sido as teorias, concepções e metodologias propostas para a compreensão da problemática ambiental urbana, mas poucas na perspectiva interdisciplinar. Neste sentido algumas novas concepções são aqui discutidas de maneira introdutória, tais como a perspectiva socioambiental do ambiente urbano, impactos, riscos e vulnerabilidade ambiental, e o SAU - Sistema Ambiental Urbano. Alguns problemas observados na Região Metropolitana de Curitiba são utilizados para exemplificar o discurso.

Palavras-chave: socioambiente urbano, risco, vulnerabilidade, Curitiba.
\end{abstract}

\footnotetext{
* Doutor em Geografia. Professor Titular do Departamento de Geografia da UFPR e ex-Coordenador do Doutorado em Meio Ambiente e Desenvolvimento. Professor Colaborador/Visitante da Universite Paris I- Sorbonne/Pantheon e da Universite de Haute Bretagne - Rennes II - France.

1 Este texto serviu também de base para uma palestra, sobre a mesma temática, proferida na Universidade de Brasília (UNB), em 30/07/2004, como parte do Seminário Internacional "A questão ambiental urbana”, organizado pelo NEUR - Núcleo de Estudos Urbanos daquela universidade. Pequenas alterações entre aquela data e a presente foram anexadas nesta versão.
} 
MENDONÇA, F. Riscos, vulnerabilidade e abordagem socioambiental urbana: uma...

\begin{abstract}
The intensification of urbanization in modern times generated numerous problems related to the quality and conditions of life in today's cities. Many have been the theories, concepts, and methodologies proposed for understanding the urban environmental issue, but few under the interdisciplinary perspective. In this sense, some new concepts are discussed here in an introductory way, such as the urban environment socio-environmental perspective; environmental impacts, risks, and vulnerability; and UES - Urban Environmental System. Some problems observed in the Curitiba Metropolitan Area (CMA) are used as examples in this paper.

Key-words: urban socio-environment, risk, vulnerability, Curitiba.
\end{abstract}

\section{Introdução}

O processo de urbanização atingiu, no final do século XX e início do XXI, índices bastante elevados, resultando que na atualidade a população do planeta é, majoritariamente, urbana. Esta condição engendra uma série de novos e complexos problemas para a compreensão e gestão do espaço e da sociedade urbanos, sendo que aqueles de ordem socioambiental encontram-se destacados no contexto das cidades, particularmente daquelas de países em condições socioeconômicas de alta complexidade, como é o caso do Brasil.

Muitas são as perspectivas teóricas e metodológicas lançadas nas últimas décadas para o estudo da urbanização e da cidade, todavia a abordagem dos problemas socioambientais urbanos ainda carece de propostas para o tratamento mais abrangente dos mesmos. A gravidade destes problemas no presente demanda, por conseguinte, maior atenção de estudiosos e gestores urbanos.

No presente texto encontram-se apresentadas, e brevemente comentadas, algumas concepções acerca de propostas recentes para a compreensão dos problemas socioambientais urbanos, bem como alguns exemplos de suas aplicações à interação entre o processo de urbanização-metropolização e os recursos hídricos da cidade de Curitiba/PR.

\section{Alguns novos conceitos envolvidos na análise dos problemas ambientais urbanos}

Problemas derivados da interação entre a sociedade e a natureza sempre marcaram os espaços de aglomeração humana, sendo mais evidentes nas cidades quando comparados aos espaços rurais contíguos ou distantes.

Por um considerável período os problemas relacionados aos espaços citadinos e ao ambiente urbano foram tratados na perspectiva de impactos ambientais urbanos. Nesta abordagem, dentro da qual inúmeras contribuições foram lançadas na perspectiva da solução dos problemas que afligem os homens nas cidades, privilegiou-se, na maioria das vezes, um tratamento de cunho naturalista; assim, ganharam destaques estudos relativos ao verde urbano, à degradação hídrica, do ar e dos solos, às inundações e deslizamentos de terras, etc.

Alguns destes estudos lançaram mão de concepções relativas a diferenças entre o ritmo dos processos da natureza e aquele da sociedade para melhor compreender os problemas ambientais urbanos; dentre os autores envolvidos neste tipo de análise pode-se citar Michel Serres (1989) e Santos (1996). Para estes o tempo da natureza é lento e o da sociedade, particularmente em sua fase tecnológica presente, rápido. Esta perspectiva evidencia considerável generalização, pois nem todo fenômeno natural se processa de forma lenta e nem toda dinâmica social se dá de forma rápida. Ritmos lentos e ritmos velozes são, sobretudo, condições relativas do estado momentâneo de cada fato ou fenômeno, assim lentidão e rapidez são observadas tanto na natureza quanto na sociedade, afinal os chamados eventos catastróficos da primeira (natural hazards), por exemplo (um terremoto, uma chuva torrencial concentrada, uma tempestade, etc), desenvolve-se de forma muito rápida, ao mesmo tempo em que a parcela da sociedade desprovida de tecnologia (a maioria da humanidade) vive à mercê do tempo lento. Pode-se, todavia, adiantar, que a parcela da população que vive no tempo lento é muito mais vulnerável aos impactos e riscos dos fenômenos ligados ao tempo 
rápido da natureza, que aquela que compõe a classe alta da sociedade; ela, por sua vez e pelo seu poder econômico e tecnológico, vive a impressão de controlar o tempo e a natureza.

A sociedade urbana, entretanto, ao vivenciar problemas de extrema gravidade para a maioria da população, manifestados em diversos processos de exclusão e injustiça social, passou a demandar uma abordagem mais complexa dos problemas ambientais ali presentes. Assim é que, ao se encontrarem expostas a fenômenos naturais, tecnológicos ou sociais impactantes e de ordem eventual e/ou catastróficos, parcelas importantes da população passaram a evidenciar condições de risco ambiental. A noção de risco ambiental liga-se, então, às ciências da natureza e às ciências da sociedade, e conduz a uma abordagem dual e de interface que concebe, como o afirmam Dubois-Maury e Chaline (2002), os riscos urbanos como produto combinado de um "àlea" (fenômeno aleatório) e de uma vulnerabilidade.

Nesta abordagem as condições de vida da população passaram a desempenhar importante papel na constituição e compreensão dos problemas ambientais urbanos e revelou, ao mesmo tempo, diferenciações claras entre a cidade formal e a cidade informal. Conforme Grazia e Queiroz (2001, p. 91)

Embora a cidade informal careça das condições necessárias à vida no cotidiano urbano, ela é acessível aos assentamentos de baixa renda que a ocupam e que desempenham um papel na estrutura econômica e social das cidades. Um agravante à qualidade de vida na cidade informal é a sua localização, frequentemente em áreas sujeitas a perigos naturais, como enchentes e deslizamentos, e a perigos tecnológicos, como contaminações e explosões, constituindo-se em risco para sua população.

Quando se trata de riscos ambientais urbanos há que se levar sempre em conta suas diferenças quanto a eventualidades e permanências, ou seja, os citadinos estão permanentemente expostos a riscos cotidianos (incêndios, transito, poluição, etc.) que não são, geralmente, tomados em conta, ao passo que os eventos extremos sim. Neste sentido Dubois-Maury e Chaline (2002, p. 17) apontam a necessidade do "estabelecimento de escalas de gravidade e de uma hierarquização dos riscos constatados ou potenciais, (...), que demandam critérios objetivos, mas também as- pectos socioeconômicos que variam muito sensivelmente de um pais a outro".

Tendo como pressuposto a concepção de impactos e riscos ambientais, e observando-se a maior complexidade dos problemas atinentes aos contextos urbanos, novas perspectivas têm sido lançadas para o entendimento dos mesmos. Neste sentido podem ser citadas as abordagens da análise socioambiental (MENDONÇA, 2002), da sustentabilidade socioambiental e da vulnerabilidade socioambiental.

Grazia e Queiroz (2001, p. 15) concebem espaço socioambiental como sendo "aquele onde vive e no qual articula indissoluvelmente sociedade e meio ambiente"; consideram eles (p. 14) que os gestores urbanos devem “... buscar a sustentabilidade socioambiental, ou seja, que a evolução da cidade não implique crescente esgotamento dos recursos naturais e exclusão de parcelas sociais". Para estes autores a condição de pobreza de uma determinada população esta estreitamente vinculada à condição de formação de riscos e de vulnerabilidade socioambiental. Assim

\begin{abstract}
...a par do comportamento especulativo do capital imobiliário, os pobres são muitas vezes impelidos a criar uma cidade ilegal nos interstícios da cidade legal, muitas vezes aproveitando áreas públicas ociosas e/ou de preservação ambiental, incapazes que são de competir no mercado formal da terra urbana. Enquanto o consumo de produtos modernos é estimulado pela mídia e facilitado pelo crédito, o mesmo não ocorre em relação à habitação. Esses moradores constroem por seus próprios meios suas moradas, sem assistência técnica ou financiamento, já que a irregularidade fundiária implica, em geral, em fortes obstáculos ao acesso ao crédito e aos programas habitacionais oficiais. As favelas, mocambos, alagados ou assentamentos clandestinos ou irregulares surgem, proliferam-se, adensam-se, constituindo a única alternativa habitacional para uma grande parte da população que enfrenta, nesse caso, a insegurança quanto à permanência e à precariedade das condições locais. (p. 44)
\end{abstract}

Esta argumentação, tendo nas relações capitalistas de produção o foco principal para a compreensão da dinâmica dos espaços nas periferias geográficas e sociológicas urbanas brasileiras, reforça as concepções de segregação social e espacial e de exclusão de parcela importante da população do país. Outro pesquisador desta temática, 
MENDONÇA, F. Riscos, vulnerabilidade e abordagem socioambiental urbana: uma...

Confalonieri (2003, p. 200), também atribui considerável importância ao envolvimento da noção de vulnerabilidade no tratamento dos problemas ambientais urbanos; na sua concepção,

o conceito de vulnerabilidade social de uma população tem sido utilizado para a caracterização de grupos sociais que são mais afetados por estresse de natureza ambiental, inclusive aqueles ligados ao clima. Os principais conceitos da vulnerabilidade têm vindo da comunidade científica que estuda os efeitos e a prevenção de impactos dos chamados desastres naturais. Assim é que Blaikie et al. (1994) definiram vulnerabilidade como as "características de uma pessoa ou grupo em termos de sua capacidade de antecipar, lidar com, resistir e recuperar-se dos impactos de um desastre climático.

Citando Pelling e Uitto (2002), Confalonieri (2003) lembra ainda que a vulnerabilidade pode ser definida como o "produto da exposição física a um perigo natural e da capacidade humana para se preparar para e recuperar-se dos impactos negativos dos desastres”. Mas há, todavia, que se assinalar, a vulnerabilidade urbana envolve, assim como os riscos urbanos, uma gama de implicações sociais, econômicas, tecnológicas, culturais, ambientais e políticas que estão diretamente vinculadas à condição de pobreza de representativa parcela da sociedade moderna. Associando a vulnerabilidade a processos econômicos e demográficos Deschamps (2004, p. 19) conclui que ela

pode ser vista como o aspecto negativo mais relevante do modelo de desenvolvimento baseado na liberalização da economia e na abertura comercial e como manifestação mais clara da carência de poder que experimentam grupos específicos, mas numerosos, da humanidade.

A noção de vulnerabilidade envolve também aspectos relativos à gestão urbana, pois, como o acenaram Dubois-Maury e Chaline (2002, p. 10), "a vulnerabilidade da cidade concerne evidentemente aquela dos homens e dos bens que ela concentra, mas ela implica, muitas vezes também, aquela de seus poderes, de sua imagem e de sua dimensão". Estes autores concebem ainda que

A vulnerabilidade urbana aos riscos, sejam eles endógenos ou exógenos, é uma noção complexa porque pode ter conteúdos humanos, econômicos, patrimoniais, tecnológicos e organizacionais que se diversificam no espaço e no tempo. O fato fundamental reside na acumulação de homens e de atividades que é própria da cidade, mas que induz à fragilidade(...) (p.21)

A todos estes "elementos-conteúdos" que enseja, a noção de vulnerabilidade urbana parece necessário evidenciar ainda que, observando-se as várias concepções, as manifestações bruscas e repentinas da natureza (natural hazards) e o meio-ambiente, constituem os dois principais responsáveis pelo maior número de problemas socioambientais urbanos. Também é verdade que sozinhos eles não respondem muito, tornando-se imperativo o envolvimento da análise socioeconômica, cultural e política da sociedade face aos riscos urbanos.

Mendonça (2004), inserindo todas estas concepções em sua análise, e buscando apontar novas perspectivas metodológicas para os estudos relativos à problemática socioambiental urbana, revisita os conceitos de ambiente urbano proposto pelo PNDU/UNOPS (1997) com seus três subsistemas (natural, social e construído), e de $S C U$ - Sistema Clima Urbano de Monteiro (1976). Considerando também a cidade como um Sistema Dinâmico, como a concebem Dubois-Maury e Chaline (2002), propõe o $S A U-$ Sistema Ambiental Urbano - como perspectiva compreensiva e metodológica para o estudo dos problemas socioambientais urbanos, esquematizado na figura 1. Esta proposta coloca em evidência o fato de que, para se elaborar estudos e intervenções na perspectiva do SAU, deve-se trabalhar com problemas emanados da interação sociedade-natureza. Assim, torna-se necessário levar em consideração que nem todos os problemas que acometem as cidades são derivados desta interação, e que muito provavelmente a maioria não o seja; a identificação de problemáticas constitui, assim, numa primeira etapa para a aplicação desta proposta.

\section{Algumas observações da vulnerabilidade socioambiental na cidade de Curitiba/PR}

Curitiba tem sido considerada, nas últimas décadas, como um exemplo de sucesso de planejamento urbano e respeito ambiental, enfim uma "cidade correta". Todavia, o papel da mídia tem sido muito mais eficaz na promoção de uma imagem positiva sobre a realidade urbano-metro- 
MENDONÇA, F. Riscos, vulnerabilidade e abordagem socioambiental urbana: uma...

FIGURA 1 - S. A. U. - SISTEMA AMBIENTAL URBANO (SIMPLIFICADO). U. E. S. - URBAN ENVIRONMENTAL SYSTEM

\begin{tabular}{|c|c|c|c|c|}
\hline \multicolumn{2}{|c|}{} & \multicolumn{2}{|c|}{} \\
\hline Relevo & Habitação & Cultura & Problemas & Planejamento \\
\hline Ar & Indústria & Economia & socioambientais & e Gestão \\
\hline Água & Comércio & Política & urbanos & Urbana \\
\hline Vegetação & e Serviços & Educação & & APLICAÇÃO \\
\hline Solo & Transporte & Tecnologia & & OUTPUT \\
\hline
\end{tabular}

(FONTE: MENDONÇA, 2004)

politana da principal área urbana do estado do Paraná do que a realidade evidencia (MENDONÇA, 2001). Nesta parte do presente texto alguns exemplos dos problemas relativos à problemática interação entre a sociedade e a natureza na cidade de Curitiba, na perspectiva da vulnerabilidade socioambiental, são apresentados.

\section{A problemática relativa à subhabitação}

A população brasileira urbanizou-se muito rapidamente, como aludido anteriormente. Este rápido processo, que revelou uma forma particular denominada de "urbanização corporativa" (SANTOS, 1993), gerou ambientes que atestam estágios diferenciados e particularmente aprofundados de degradação do ambiente e das condições e qualidade de vida dos citadinos. As cidades brasileiras passaram a atestar, sobretudo a partir das três últimas décadas, expressiva concentração populacional.

Curitiba, que após sua elevação à condição de metrópole em meados da década de 1970, passa a atestar um dos mais expressivos crescimentos dentre as capitais e regiões metropolitanas do país, posicionando-se dentre as grandes cidades brasileiras em meados da década de 1990. Como a tabela 1 evidencia, ela ocupa a $6^{\text {a }}$ posição no ranking nacional. Este rápido crescimento, fruto de um intenso processo de citymarketing (MENDONÇA, 2001), trouxe para a cidade uma considerável gama de migrantes. Aqueles portadores de baixo preparo técnico-educacional e menos aquinhoados financeiramente tiveram que se sujeitar ao jogo estabelecido, dentre outros, pelo mercado imobiliário da cidade.

Assim, uma proliferação de bairros periféricos aos tradicionais, e uma considerável quantidade de ocupações irregulares de áreas públicas e/ou privadas para habitação passaram, também rapidamente, a caracterizar o espaço urbano da Região Metropolitana de Curitiba. Nestas novas localidades a população passou a conviver com diversos tipos de impactos e riscos ambientais encontrando-se, em boa parte das vezes, em condições de vulnerabilidade socioambiental.

As franjas urbanas evidenciam a concentração da pobreza e portanto da vulnerabilidade socioambiental metropolitana, pois, conforme o apontaram Grazia e Queiroz (2001, p. 24), "mantém-se o padrão segregador da urbanização brasileira; o crescimento nas periferias metropolitanas é muito maior que nos núcleos, revelando a impossibilidade da maior parte da população ter acesso às áreas equipadas, agravando as condições de vida". Curitiba reflete, de maneira clara, esta lógica, o que se observa quando se analisa os dados relativos à evolução da população vivendo em condições de subhabitação na cidade (cerca de 12\% do total no ano 2000 - tabela 2). Neste âmbito o conceito de centro e periferia geográfica perde em parte seu signifi- 
MENDONÇA, F. Riscos, vulnerabilidade e abordagem socioambiental urbana: uma...

TABELA 1 - BRASIL - CLASSIFICAÇÃO DAS CIDADES (2000). BRAZIL - CITY CLASSIFICATION (2000)

\begin{tabular}{|c|c|c|c|c|}
\hline METRÓPOLES & N. Munic.** & Hierarquia & \% Pop. Br & Popul. 1996 \\
\hline São Paulo* & 39 & \multirow{2}{*}{$\begin{array}{l}\text { Metrópole } \\
\text { Global }\end{array}$} & \multirow[t]{2}{*}{17,32} & 16.666 .986 \\
\hline Rio de Janeiro & 21 & & & 10.532 .382 \\
\hline Salvador* & 11 & \multirow{7}{*}{$\begin{array}{l}\text { Metrópole } \\
\text { Nacional }\end{array}$} & \multirow{7}{*}{13,05} & 2.776 .217 \\
\hline Belo Horizonte & 25 & & & 3.829 .042 \\
\hline Fortaleza* & 11 & & & 2.639 .180 \\
\hline Brasília & 11 & & & 2.358 .069 \\
\hline Curitiba* & 16 & & & 2.348 .559 \\
\hline Recife* & 16 & & & 3.258 .388 \\
\hline Porto Alegre* & 24 & & & 3.291 .680 \\
\hline Manaus & 1 & \multirow{5}{*}{$\begin{array}{c}\text { Metrópole } \\
\text { Regional }\end{array}$} & \multirow[t]{4}{*}{4,68} & 1.157 .357 \\
\hline Belém* & 4 & & & 1.628 .746 \\
\hline Goiânia & 6 & & & 1.416 .942 \\
\hline Campinas & 17 & & & 1.992 .157 \\
\hline Total & 202 & & $34,31 \%$ & 53.905 .705 \\
\hline
\end{tabular}

FONTE: IPEA - INSTITUTO DE PESQUISAS ECONÔMICAS APLICADAS (2000).

* Trata-se das 9 regiões metropolitanas oficiais estabelecidas desde os anos 1970 mais o Distrito Federal.

** Número de municipalidades definido segundo a pesquisa do IPEA (2000) que é, para certos casos, diferente do número estabelecido pelo Estado (oficial).

cado espacial, e explicita muito mais uma condição de vida, uma posição na hierarquia socioeconômica, que uma condição de lugar, pois torna-se quase impossível ler o espaço a partir da noção clássica de centro e periferia, ou seja, os pobres não estão somente na periferia urbana. p. 103):

Na concepção destes autores (GRAZIA; QUEIROZ, 2001,

devido à densidade populacional do espaço urbano, seus desequilíbrios ambientais tendem a gerar, ou intensificar, as desigualdades já existentes. Os conflitos socioambientais aqui passam a se constituir, então, em questões de injustiça ambiental caracterizadas a partir da distribuição espacial da população.
Desta maneira torna-se possível, ao se inter-relacionar condições de impactos, riscos ambientais e pobreza urbana, sobretudo periferias das cidades, em vulnerabilida-des socioambientais urbanas, donde os exemplos aqui evidenciados na cidade de Curitiba compõem apenas parte de um grave quadro de condições e qualidade de vida urbana brasileira.

Nas palavras destes últimos autores (p. 45) tem-se que

o processo de produção das cidades ilegais parece vir se acentuando no quadro de crise das últimas décadas. A população favelada brasileira mais do que dobrou entre 1980 (2.248.336 habitantes) e 1991 (5.020.517 habitantes), sendo que as favelas cresceram, no período, mais 
MENDONÇA, F. Riscos, vulnerabilidade e abordagem socioambiental urbana: uma...

TABELA 2 - POPULAÇÃO EM CONDIÇÕES DE SUBHABITAÇÃO EM CURITIBA/PR. EVOLUÇÃO 1970 - 2000. PEOPLE LIVING IN UNHEALTHY CONDITIONS IN CURITIBA-PR. FROM 1970 TO 2000.

\begin{tabular}{|c|c|c|}
\hline Data & $\begin{array}{c}\text { População em } \\
\text { Subhabitação }\end{array}$ & \% População Total \\
\hline $\mathbf{1 9 7 0}$ & 11.000 & 1,7 \\
\hline $\mathbf{1 9 8 0}$ & 34.000 & 3,3 \\
\hline $\mathbf{1 9 9 1}$ & 110.000 & 7 \\
\hline $\mathbf{2 0 0 0}$ & 200.000 & 12 \\
\hline
\end{tabular}

FONTE: IBGE, IPPUC, Ippardes.

no Nordeste (de $15,24 \%$ para $25,75 \%$ ) e no Norte (de $3,15 \%$ para $9,52 \%)$. No Sudeste, onde há uma forte diminuição das taxas de crescimento populacional, as grandes cidades têm visto sua população favelada crescer em ritmo mais acentuado do que a população total: na cidade do Rio de Janeiro, na década de 1980, a população favelada cresceu $32 \%$, enquanto a total, $17,7 \%$; em Belo Horizonte, entre 1980 e 1991, estes números foram de, respectivamente, 58,9\%, contra 13,5\% (RIBEIRO, 1994). Em São Paulo, a população favelada passou de $1,2 \%$ da total em 1973 para 8,9\% em 1993. Recife, Rio de Janeiro e São Paulo eram as metrópoles com maior número de favelas.

Ao elaborar estudo sobre a vulnerabilidade socioambiental na Região Metropolitana de Curitiba Deschamps (2004, p. 142) concluiu

que há uma estreita relação entre a localização espacial dos grupos que apresentam desvantagens sociais e aquelas áreas onde há o risco de ocorrer algum evento adverso, ou seja, populações socialmente vulneráveis se localizam em áreas ambientalmente vulneráveis.

Fica evidente, numa observação mesmo que rápida dos dados apresentados na tabela 2 - relativos à população que vive em condições de subhabitação em Curitiba, que os percentuais desta realidade encontram-se bastante próximos daqueles de outras localidades do país. Todavia, ainda que a temporalidade dos dados seja diferenciada, eles re- gistram uma expressiva elevação na última década, e constituem testemunho de uma problemática que demanda considerável atenção dos gestores públicos. Mendonça (2003) e Deschamps (2004) evidenciaram a preocupante situação de risco e vulnerabilidade na qual se encontra grande parcela da população curitibana e de sua região metropolitana, quando considerados os processos de precipitação e inundações na área.

\section{A problemática relação urbanização - recursos hídricos: A qualidade da água ${ }^{2}$}

Os recursos hídricos apresentam considerável disponibilidade e abundância no âmbito da Região Metropolitana Curitiba. Essa abundância fez com que o crescimento da cidade se realizasse em larga escala contando com o abastecimento d'água a partir de fontes locais, próximas aos centros de consumo; no entanto, há algumas décadas o suprimento tem apresentado comprometimento.

$\mathrm{Na}$ porção superior da bacia do rio Iguaçu, mais especificamente do alto Iguaçu, a situação dos mananciais já se apresentava crítica desde o início da década de 1990, originária da intensa dinâmica da urbanização metropolitana dessa época, que tem como característica a expansão da malha urbana para áreas sem infra-estrutura, o que configura o processo de periferização. A Comec realizou, em 1992, um levantamento das ocupações irregulares na região e constatou que aproximadamente $5 \%$ da população se encontrava nesta situação. A pesquisa foi atualizada em

2 Parte do conteúdo deste item foi publicada na Revista GEOUSP, segundo semestre de 2003. 
MENDONÇA, F. Riscos, vulnerabilidade e abordagem socioambiental urbana: uma...

1997 e os resultados mostraram que se elevou para $12 \%$ o percentual da população vivendo em áreas ocupadas irregularmente (como visto anteriormente), sendo que em torno de um terço dessas ocupações encontravam-se em áreas de proteção de mananciais. Se a RMC tem hoje uma população de 2.725.629 (IBGE, 2000), estes $12 \%$ equivaleriam a 327.075 habitantes, dos quais 109.025 estão vivendo em ocupações irregulares nas áreas de mananciais (AMARAL, 2002).

$\mathrm{Na}$ passagem pela $\mathrm{RMC}$, o rio Iguaçu recebe uma significativa quantidade de substâncias poluidoras de origens domésticas, industriais e do escoamento difuso, sendo a maioria sem tratamento. A carga de poluição da região metropolitana tem grande influência na qualidade da água do rio Iguaçu, que é indicada através das altas concentrações de material orgânico e de nutrientes, quando este passa pela RMC. De acordo com o sistema de classificação de qualidade da água, utilizado no estado do Paraná, o rio Iguaçu, embora enquadrado na Classe 2, encontra-se de fato na Classe 4 , a mais baixa categoria para a qualidade conforme o uso.

Os rios que cortam a área urbanizada do município sede da região metropolitana ${ }^{3}$ são os que apresentam os mais elevados índices de degradação, classificados como possuindo qualidade de regular a ruim segundo o IQA, ${ }^{4}$ parâmetro utilizado internacionalmente para aferir a qualidade da água dos cursos hídricos. Esta degradação está relacionada principalmente ao esgotamento sanitário, sobretudo o doméstico, sendo que o industrial também é um considerável contribuinte para a queda da qualidade das águas do município. Dados oficiais resultantes de análises nos últimos anos revelam que os rios que passam pela área urbana de Curitiba e municípios limítrofes, sendo os rios Bacacheri, Belém, Padilha, Barigüi, Atuba e Iguaçu apresentam a qualidade de suas águas como razoável a ruim, portanto altamente comprometidas (tabela 3 ).

Quando se analisa os dados apresentados na tabela 3, particularmente a temporalidade de alguns dos parâmetros aferidos, por exemplo o período que vai de 1987 a 1993 ou 1994, e se identifica que a criação do slogan "Curitiba Capital Ecológica"5 se dá paralela e concomitantemente à constatação da alta poluição dos rios (caracterizados como de qualidade ruim e pertencentes à classe 4/ Resolução n. 20 do Conama), evidencia-se a não correspondência entre a imagem e a realidade.

A elevada degradação dos cursos hídricos de uma cidade revela uma insuficiente e ineficaz política de saneamento ambiental urbano, característica dos países não desenvolvidos ou em estágio de desenvolvimento complexo, nos quais o descaso dos governantes para com a qualidade de vida da população se manifesta, dentre outros, na parcial e insatisfatória cobertura da rede de água tratada e de esgotamento sanitário. Nestes países se observa, principalmente, uma maior atenção do poder público ao sucesso econômico e uma considerável desatenção aos aspectos da promoção social - das condições e qualidade de vida da população.

Na cidade de Curitiba, embora cerca de $90 \%$ da população tenha acesso à água tratada, somente cerca de $60 \%$ dos domicílios são servidos pela rede de esgotamento sanitário. Há, portanto, uma expressiva parte da população (cerca de $40 \%$, ou 700.000 pessoas) que lança seus esgotos em fossas, na rede de águas pluviais através de ligações clandestinas ou mesmo diretamente nos cursos hídricos; toda esta ação resulta em degradação da qualidade das águas dos rios e da água subterrânea, e compromete seriamente a qualidade de vida da população.

Como reflexo de sua condição de cidade localizada num país não desenvolvido, a distribuição espacial da rede de água tratada e de esgotamento sanitário revela, de forma clara, a exclusão social e a concentração dos privilégios sociais numa determinada parcela da população. É exatamente na área da periferia urbana de Curitiba, além de alguns locais pericentrais de concentração da subhabitação

3 A revista do CREA/PR (Conselho Regional de Engenharia, Arquitetura e Agronomia do Paraná) traz, em seu n. 10, ano 3, set. 2000, várias reportagens relativas à qualidade das águas de Curitiba e RMC, por ocasião do acidente de derramamento de óleo da Petrobrás no rio Iguaçu em jul. 2000. Uma das reportagens afirma “...A gravidade é tanta que há muito tempo os ecologistas (e também o governo) sabem que o Barigui e o Iguaçu nos limites da Região Metropolitana, estão praticamente mortos, tal é a carga de resíduos industriais e lixo orgânico carreada diariamente, sem que órgãos públicos competentes se pronunciem (...) (p. 21).

4 IQA - Índice de Qualidade da Água, desenvolvido pela National Sanitation Foundation (USA), índice calculado para atribuir uma nota à qualidade da água (varia entre 0 e 100), no qual nove parâmetros são considerados: oxigênio dissolvido (OD), demanda bioquímica de oxigênio (DBO5), coliformes fecais, pH, temperatura, nitrogênio total, fósforo total, turbidez e sólidos totais. Correlacionando-se os valores do IQA com a Resolução n. 20 do Conama tem-se que valores entre 80 -100 (ótima) corresponde à Classe 1, entre 52-79 (boa) às Classes 2 e 3, entre 37-51 (razoável) à Classe 4 e entre 0-36 (ruim) quando excedem os limites da Classe 4.

5 Conforme documento do IPPUC (Instituto de Pesquisa e Planejamento Urbano de Curitiba), Curitiba teria criado uma Escola de Planejamento Ecológico resultante da boa qualidade ambiental da cidade baseada na relação área verde/habitante associada ao transporte urbano eficaz. (IPPUC, 1992). 
MENDONÇA, F. Riscos, vulnerabilidade e abordagem socioambiental urbana: uma...

TABELA 3 - IQA (ÍNDICE DE QUALIDADE DAS ÁGUAS) DOS PRINCIPAIS CURSOS HÍDRICOS DE CURITIBA - 1987/1998. WQI (WATER QUALITY INDEX) OF CURITIBA'S MAIN WATERWAYS - 1987/1988

\begin{tabular}{|c|c|c|c|c|c|}
\hline $\begin{array}{c}\text { CURSO } \\
\text { HÍDRICO }\end{array}$ & $\begin{array}{c}\text { PONTO COLETA } \\
\text { AMOSTRAS }\end{array}$ & $\begin{array}{c}\text { LEVANT. } \\
\text { DADOS }\end{array}$ & IQA & $\begin{array}{c}\text { LEVANT. } \\
\text { DADOS }\end{array}$ & IQA \\
\hline \multirow{3}{*}{ ATUBA } & Terminal A. Camargo & $1993-95$ & Ruim* & $1996-98$ & Ruim* \\
\cline { 2 - 6 } & Jusante Cor. Monjolo & $1993-94$ & Razoável & $1996-98$ & Razoável \\
\hline \multirow{3}{*}{ IGUAÇU } & Ponte BR-277 & $1987-94$ & Razoável* & $1996-98$ & Razoável* \\
\cline { 2 - 6 } & Araucária & $1987-94$ & Ruim* & - - - - & - - - - \\
\cline { 2 - 6 } & ETE SANEPAR & $1987-94$ & Ruim* & $1996-98$ & Ruim* \\
\cline { 2 - 6 } & Boichininga & $1993-94$ & Boa & $1996-98$ & Boa \\
\cline { 2 - 6 } & Av. Manoel Ribas & $1993-94$ & Razoável & $1996-98$ & Razoável \\
\cline { 2 - 6 } & Conectora 5 (Semin.) & $1987-94$ & Razoável* & $1996-98$ & Razoável* \\
\cline { 2 - 6 } & Av. João Bettega & $1993-94$ & Ruim & $1996-98$ & Ruim \\
\hline \multirow{3}{*}{ BELÉM } & Ponte da Caximba & $1987-95$ & Ruim* & $1996-98$ & Ruim* \\
\cline { 2 - 6 } & Prado Velho & $1987-94$ & Ruim* & $1996-98$ & Ruim \\
\cline { 2 - 6 } & Rodolfo Bernardelli & $1987-95$ & Ruim & $1996-98$ & Ruim \\
\hline \multirow{2}{*}{ BACACHERI } & Mont. Pq. S. Lourenço & $1993-94$ & Ruim & $1996-98$ & Ruim \\
\cline { 2 - 6 } & Parque Bacacheri & $1993-94$ & Ruim & $1996-98$ & Ruim* \\
\hline Á. VERDE & Jusante BR-116 & $1993-94$ & Ruim & $1996-98$ & Ruim \\
\hline V. PAROLIM & Foz & $1993-94$ & Ruim & - - - - & - - - - \\
\hline IVO & Foz & $1993-94$ & Ruim & - - - - & - - - - \\
\hline V. FANY & Foz & $1993-94$ & Ruim & - - - - & - - - - \\
\hline PADILHA & Jardim Paranaense & $1993-94$ & Ruim & - - - - & - - - - \\
\hline
\end{tabular}

FONTE: SUDERHSA, 1997 E DADOS FORNECIDOS EM 2000.

* IQA predominante, podendo haver outros no período.

nesta cidade, que se registram a escassez dos referidos recursos e equipamentos urbanos. É também a população destas áreas, sobretudo crianças, aquela que registra os mais elevados índices de doenças relacionadas à insalubridade do ambiente decorrente da falta ou insuficiência de saneamento básico.

Através destes processos citados anteriormente constata-se que os municípios limítrofes a Curitiba receberam grandes contingentes populacionais (o aglomerado urbano de Curitiba concentra cerca de 2,3 milhões de habitantes), ocasionando sérios conflitos entre o uso e ocupação do solo e a qualidade da água dos mananciais. É consensual a crença de que os mananciais para abastecimento público devam localizar-se distantes das cidades a serem abastecidas. A proximidade dos mesmos, como ocorre na RMC, apresenta um sério conflito que é representado pela expansão desordenada da urbanização ("urbanização corporativa") sobre os mananciais da região.

\section{Considerações finais}

A abordagem da problemática socioambiental urbana a partir da perspectiva dos impactos, riscos, Sistema Ambiental Urbano e vulnerabilidade socioambiental coloca-se como uma instigante construção teórico-metodológica aos estudiosos e gestores da cidade do presente. Estas propostas constituem ainda, no seu geral, estágios relativamente embrionários do tratamento dos problemas socioambientais urbanos numa nova perspectiva, restando dos pesquisadores urbanos seu desenvolvimento e aprofundamento.

Inúmeros exemplos de realidades que espelham condições de impactos, riscos e vulnerabilidades socioambientais podem ser evocados acerca de cidades de países não desenvolvidos. A lógica da urbanização no contexto de tais países é muito parecida no tocante à produção dos espaços urbanos ali presentes e, de forma particular, da miríade de 
MENDONÇA, F. Riscos, vulnerabilidade e abordagem socioambiental urbana: uma...

problemas que lhes caracterizam. Assim, a constatação da degradação ambiental e da qualidade/condições de vida compõe um só mosaico, sobre o qual a aplicação da perspectiva da vulnerabilidade socioambiental pode em muito contribuir para realçar a gênese e evolução dos problemas atinentes.

Os exemplos apresentados concernentes à cidade de Curitiba e Região Metropolitana de Curitiba, nos quais fica evidente a interação entre impactos e riscos de inundações associados a áreas de concentração da pobreza/ subhabitações, colocam em questão a veiculação de cidade exemplo de sucesso do planejamento urbano. Boa parte da cidade, região metropolitana e de sua população evi- denciam, de forma flagrante, condições de expressiva vulnerabilidade socioambiental.

Muitas são as soluções possíveis para o equacionamento dos problemas socioambientais das cidades do presente. Todavia, parece que não se logrará sucesso se não houver a criação e aplicação de uma gestão urbana com participação social, sem o fortalecimento do papel do Estado (do setor público) na condução do processo, e sem cidadania e democracia... Afinal, as cidades, espaço e modo de vida que fascina a maior parte dos homens do presente, devem ser convertidas (todas elas), em ambientes de prazer e boas realizações para a maior parte da população.

\section{REFERÊECIAS}

AMARAL, S. B. Aspectos da relação entre uso do solo e qualidade da água na bacia do rio Pequeno - São José dos Pinhais/PR..Curitiba, 2002. Dissertação (Mestrado em Geografia) - Universidade Federal do Paraná.

CONFALONIERI, U. E. C. Variabilidade climática, vulnerabilidade social e saúde no Brasil. Revista Terra Livre, São Paulo, ano 19, v. 1, n. 20, p. 193-2004. jan./jul.2003.

DESCHAMPS, M. V. Vulnerabilidade socioambiental na região metropolitana de Curitiba/PR. Curitiba, 2004. Tese (Doutorado em Meio Ambiente e Desenvolvimento) - Universidade Federal do Paraná.

DUBOIS-MAURY, J.; CHALINE, C. Les risques urbains. Paris: Armand Colin, 2002.

GRAZIA, G.; QUEIROZ, L. L. et al. O desafio da sustentabilidade urbana. Rio de Janeiro: FASE/IBASE, 2001. (Série Cadernos Temáticos, n. 5).

MENDONÇA, F. Geografia socioambiental. In: Elementos de epistemologia da geografia contemporânea. Curitiba: UFPR, 2002.

A abordagem interdisciplinar da problemática ambiental urbana-metropolitana: esboço metodológico da experiência do Doutorado em MA\&D da UFPR sobre a RMC - Região Metropolitana de Curitiba. Desenvolvimento e Meio Ambiente - Cidade e Ambiente Urbano. Curitiba: UFPR, n. 3, 2001 .

2004.

Impactos socioambientais urbanos. Curitiba: UFPR,

.; LIMA, C. A. Planejamento urbano-regional e crise ambiental: região metropolitana de Curitiba/PR. São Paulo em perspectiva, São Paulo, v. 15, n. 1, p. 135-143, 2001.

PNUD - Programa de las Naciones Unidas para el Desarrollo; UNOPS - Oficina de Servicios para Proyetos de las Naciones Unidas. Proyecto regional de capacitación en gestión ambiental urbana. Guia metodológica de capacitación en gestión ambiental urbana para universidades de América Latina y el Caribe. Nova York: UNDP/UNOPS, 1997.

SANTOS, M. A urbanização brasileira. São Paulo: Hucitec, 1993.

A natureza do espaço. São Paulo: Hucitec, 1996.

SERRES, M. Le contrat naturel. Paris: Flammarion, 1987. La legende das anges. Paris: Flammarion, 1995. 